\title{
ASSESSMENT OF THE EFFECT OF MULTIMODAL PREEMPTIVE ANALGESIA IN CHILDREN
}

\author{
MN ZAMAN ${ }^{1}$, PS MAJUMDER ${ }^{2}$, MMM PERVEZ $^{3}$, MAB AKAN $^{4}$, M ANISUZZAMAN ${ }^{5}$, MN ISLAM $^{6}$, AM $^{2}$ \\ SHAHINOOR ${ }^{7}$
}

\begin{abstract}
Preemptive analgesia, an evolving clinical concept, involves the introduction of an analgesic regimen before the onset of noxious stimuli, with the goal of preventing sensitization of the nervous system to subsequent stimuli that could amplify pain. Pain is inevitable after any surgery. Surgery offers the most promising setting for preemptive analgesia because the timing of noxious stimuli is known.

This prospective double blind study included 60 children (30 in each group), undergoing major surgery under general anesthesia. Each patient in the study group (Group II) received pre-emptive analgesia (Local anesthesia, per-rectal diclofenac just prior to surgery, per-rectal paracetamol 2 hours prior to surgery) and regular pattern of postoperative pain intervention with per rectal diclofenac and per rectal or oral paracetamol in different phases of postoperative pain management up to 48 hours.

On the other hand, each patient of control group (Group I) received pre-emptive analgesia (Local anesthesia \& per-rectal diclofenac) regular pattern of postoperative pain intervention with per-rectal diclofenac in different phases of postoperative pain up to 48 hours.

The degree of postoperative pain was assessed by universal pain assessment tools (VAS) at defined intervals. Most children in the study group (Group II) has significantly better postoperative pain control with
\end{abstract}

1. Dr. Md. Nooruzzaman, Medical Officer, OSD, DG Health

2. Dr. Partha Sarathy Majumder, Resident Surgeon, Noakhali Medical College

3. Dr. MM Masud Pervez, Medical Officer, Department of Urology, BIRDEM, Dhaka

4. Dr. Md. Abu Bakar Akan, Medical Officer, Upozila Health Complex, Swarupkati, Pirojpur

5. Dr. M Anisuzzaman, Registrar, Department of Surgery, Holy Family Red Crescent Hospital, Dhaka

6. Dr. Md. Nazrul Islam, Medical Officer, Department of Paediatric Surgery, BSMMU,

7. Dr. AM Shahinoor, Medical Officer, Department of Paediatric Surgery, BSMMU

Correspondence to: Dr. Md. Nooruzzaman, Medical Officer, OSD, DG Health, Dhaka, E-mail: mnzamandj3@gmail.com only mild pain at $4^{\text {th }}$ postoperative hours. It is obvious that less pain in Group-Il due to synergistic effect of paracetamol and diclofenac. In the control group (Group I) there was persistence of mild pain throughout the observation period i.e. up to 48 postoperative hours. The breakthrough pain occurred more in latter group, two patients needed rescue analgesia. Whereas no patient experienced breakthrough pain requiring rescue analgesia in study group (Group II).

Therefore this study concludes that administrations of multimodal pre-emptive analgesia control pain more effectively in children in view of both the degree of pain control and sustainability of pain free state.

Keywords: Multimodal, Preemptive, Analgesia, Post-operative pain

\section{Introduction}

Pain is not only a sensation but also an unpleasant experience. Pain is inevitable after any operation. Pain control is a basic human right, especially when pain control has become effective and organized day by day. For this reason seeking of excellent pain control policy has become a continuous process ${ }^{1}$. We know that pain sensation and experience is a work of the CNS, even though pain originates from various parts of the body. Pain impulses which originate in the trauma area pass to CNS through various steps ${ }^{2}$.

We know that there are many pharmacological ways to prevent the progress of pain stimulus at many steps of its pathway. What is important is that the ways should be effective, without adverse effects and cheap.

As any operation initiates pain, prevention of pain impulses is done at the starting point to control pain effectively. This concept is named pre-emptive analgesia ${ }^{3}$.In this protocol, actions are started to control pain before operation by preventing pain impulses from originating. 
Since observation has shown that we can prevent pain at various steps, better control of pain can be achieved by the application of drugs effective in each steps of the pain propagation pathway 4

Generally, infiltration of local anesthetic agent at the proposed site of incision prevents primary pain stimulus ${ }^{5}$. At the same time, application of NSAIDs controls the release of Prostaglandin, an intermediate common pain mediator, which controls pain stimulus at the early stages of pain pathway ${ }^{6}$. Despite these measures, effective pain control is seldom achieved.

We know that opioids analgesics act in the CNS and control post operative pain effectively. But this drug is costly and it has some serious side effects like drowsiness, nausea, vomiting, etc. In addition opioids also have a risk of addiction. Besides, the route of administration of this drug is injection ${ }^{7}$.

On the other hand, easily available paracetamol blocks pain impulse at the level of the spinal cord by its action over NMDA receptors. Paracetamol also has convenient routes of administration- oral and per-rectal. The side effects of paracetamol are not usual and not serious and paracetamol also has no risk of addiction.

From this known information a new concept is borneInfiltration of local anesthetic at the incision area and application of per-rectal paracetamol along with preemptive per-rectal diclofenac can be a better protocol for control of postoperative pain in children.

This study was carried out to see the practical effectiveness of this concept and wanted to observe and quantify the effect of multimodal preemptive analgesia.

\section{Methods and Materials}

The dose/frequency of diclofenac/paracetamol was maintained within the normal daily dose throughout period. It is an interventional, prospective and double blind study.

Sampling- Purposive from population and random selection of group.

Inclusion criteria -5 to 15 years, ASA-PS-I, undergoing major elective surgery.

Sample size-total sixty(60), divided into two equal arms i.e. Group-I(control group), and Group-II(study grpup).

Verbal and written informed consent was obtained from parents/legal guardian of each child.

Observation was made by VAS and data was collected with a pre-set data sheet.

Various levels of pain was explained to the patients with the help of VAS and the patients were asked to mark the line at the point that best represented the intensity of his /her pain.

One investigator ensured that correct drugs and doses were administered. He was not involved in any aspect of the assessment of pain of patients.

Another investigator was given training about pain assessment and his pain assessment quality was tested by dummy patient.

He was involved only for pain assessment but he was totally blind about analgesic protocol.

The rescue analgesia was assessed by a recovery doctor.

\section{Sleeping children were not disturbed and were} considered pain free.

Pain control protocol

Group-I

Under general anesthesia, single rectal dose of Diclofenac $(1 \mathrm{mg} / \mathrm{kg})$ was administered after the patient intubated but before painting the operative site ,infiltration of local anesthetic(lignocaine $2 \%$ and bupivacaine $0.5 \%$ ) at incision line was given prior to skin incision

Group II

Single rectal dose of paracetamol $(30 \mathrm{mg} / \mathrm{kg})$ was given 2-3 hours prior to the operation

Rest of the pre-emptive analgesic practice was the same as that of group I

Analgesia was maintained in the postoperative ward with per rectal administration of diclofenac up to 48 postoperative hours and then orally.

For patients of group II per rectal/oral paracetamol was added with diclofenac.

Postoperative pain was assessed with the help of VAS at $4^{\text {th }}, 12^{\text {th }}, 24^{\text {th }}$, and, $48^{\text {th }}$ postoperative hours in both groups.

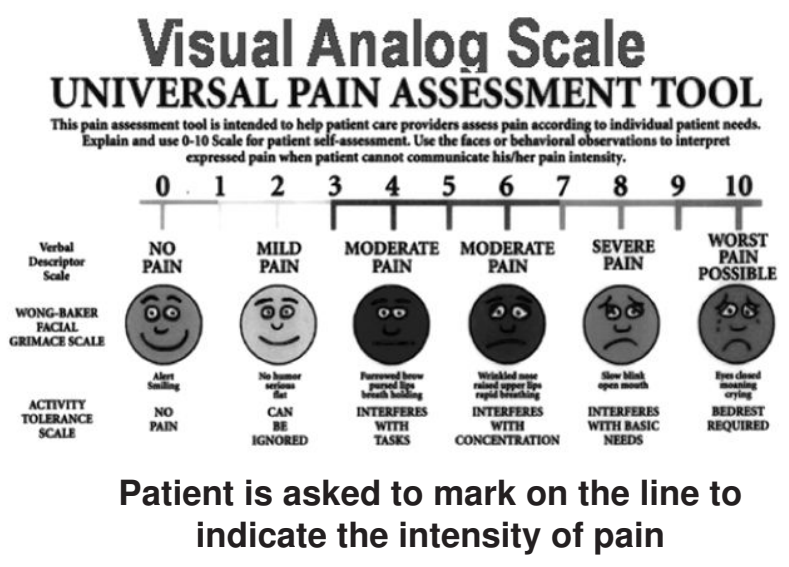

Fig.-1: 


\section{Results}

Age sex and birth weight were not statistically significant ( $p>0.05$ ) between two Groups in unpaired ' $t$ ' test.

The mean on coming round 4 hours was found ( $14 \pm$ 5.2) with range from 0 to 30 in Group I and (5.7 \pm 2.8$)$ with range from 0 to 10 in Group II. The mean on 12 hours was found $(8.3 \pm 3.8)$ with range from 0 to 20 in Group I and ( $3.3 \pm 1.8)$ with range from 0 to 10 in Group II .The mean on 24 hours was found $(3.7 \pm 1.5)$ with range from 0 to 20 in Group I and $(1.9 \pm 0.8)$ with range from 0 to 10 in Group II. The mean 48 hours was found $(1.4 \pm 0.6)$ with range from 0 to 20 in Group
I and $(0.9 \pm 0.3)$ with range from 0 to 10 in Group II. The degree of pain was significantly higher in the Group I at each defined intervals. The maximum intensity of pain was during the first 4 post operative hour's and pain significantly reduced from 4 hours to 48 post operative hours. Other results depicted in the table.

In the Group I, (6.7\%) and Group II (54\%) had pain free at $4^{\text {th }}$ post operative hour, and Group I (33.3\%) and Group II (73.4\%) had pain free $12^{\text {th }}$ postoperative hour, and Group I (63.3\%) and Group II (80\%) had pain free $24^{\text {th }}$ postoperative hour, and Group I (85.3\%) and Group II (93.4\%) had pain free $48^{\text {th }}$ post operative hour.

Table-I

Distribution of the study patients according to follow up vas score $(n=60)$

\begin{tabular}{|c|c|c|c|c|c|}
\hline \multirow[t]{2}{*}{ Follow-up } & \multicolumn{2}{|c|}{ Group I $(n=30)$} & \multicolumn{2}{|c|}{ Group II(n=30) } & \multirow[t]{2}{*}{ Pvalue } \\
\hline & $\mathrm{N}$ & $\%$ & $\mathrm{n}$ & $\%$ & \\
\hline \multicolumn{6}{|l|}{ On coming round 4 hours } \\
\hline Mean \pm SD & 16 & \pm 5.2 & 6.7 & \pm 2.8 & $0.001^{\mathrm{s}}$ \\
\hline Range (min-max) & $(0$ & $-30)$ & $(0$ & $-10)$ & \\
\hline \multicolumn{6}{|l|}{12 hours } \\
\hline Mean \pm SD & 9.3 & \pm 3.8 & 4.3 & \pm 1.8 & $0.017^{\mathrm{s}}$ \\
\hline Range (min-max) & $(0$ & $-20)$ & $(0$ & $-10)$ & \\
\hline \multicolumn{6}{|l|}{24 hours } \\
\hline Mean \pm SD & 3.7 & \pm 1.5 & 0.9 & \pm 0.8 & $0.001^{\mathrm{s}}$ \\
\hline Range (min-max) & $(0$ & $-20)$ & $(0$ & $-10)$ & \\
\hline \multicolumn{6}{|l|}{48 hours } \\
\hline Mean \pm SD & 1.4 & \pm 0.6 & 0.5 & \pm 0.2 & $0.006^{s}$ \\
\hline Range (min-max) & $(0$ & $-20)$ & (0 & $-10)$ & \\
\hline$P$ value & $P$ value & & & & \\
\hline 4 vs 12 hours & $0.001^{\mathrm{s}}$ & $0.001^{\mathrm{s}}$ & & & \\
\hline 4 vs 24 hours & $0.001^{\mathrm{s}}$ & $0.001^{\mathrm{s}}$ & & & \\
\hline 4 vs 48 hours & $0.001^{\mathrm{s}}$ & $0.001^{\mathrm{s}}$ & & & \\
\hline
\end{tabular}

$\mathrm{S}=$ Significant, NS=Not significant

$P$ value reached from unpaired t-test.

Follow up mean VAS score at defined interval. 
Table-II

Breakthrough VAS score

\begin{tabular}{|c|c|c|c|c|c|}
\hline \multirow[t]{2}{*}{ VAS score } & \multicolumn{2}{|c|}{ Group I (n=30) } & \multicolumn{2}{|c|}{ Group II (n=30) } & \multirow[t]{2}{*}{ Pvalue } \\
\hline & $\mathrm{n}$ & $\%$ & $\mathrm{n}$ & $\%$ & \\
\hline \multirow{2}{*}{\multicolumn{6}{|c|}{$\begin{array}{l}\text { Breakthrough pain } \\
1^{\text {st }}\end{array}$}} \\
\hline & & & & & \\
\hline Mean \pm SD & 12.33 & \pm 4.28 & 1.67 & \pm 0.33 & $0.001^{\mathrm{s}}$ \\
\hline Range (min-max) & (10.00 & $-30.00)$ & $(0.00$ & $-10.00)$ & \\
\hline \multicolumn{6}{|l|}{$2^{\text {nd }}$} \\
\hline Mean \pm SD & 0 & & & 0 & \\
\hline Range (min-max) & 0 & & & 0 & \\
\hline
\end{tabular}

Table-III

Follow-up pain status

\begin{tabular}{|c|c|c|c|c|c|}
\hline \multirow[t]{2}{*}{ Variables } & \multicolumn{2}{|c|}{ Group I $(n=30)$} & \multicolumn{2}{|c|}{ Group II $(n=30)$} & \multirow[t]{2}{*}{ P value } \\
\hline & $\mathrm{n}$ & $\%$ & $\mathrm{n}$ & $\%$ & \\
\hline \multicolumn{6}{|l|}{4 hour } \\
\hline Present & 28 & 93.3 & 12 & 46 & $0.001^{\mathrm{s}}$ \\
\hline Absent & 2 & 6.7 & 18 & 54 & \\
\hline \multicolumn{6}{|l|}{12 hour } \\
\hline Present & 21 & 66.7 & 8 & 26.6 & $0.028^{s}$ \\
\hline Absent & 10 & 33.3 & 22 & 73.4 & \\
\hline \multicolumn{6}{|l|}{24 hour } \\
\hline Present & 10 & 36.7 & 4 & 16.7 & $0.037^{\mathrm{s}}$ \\
\hline Absent & 19 & 63.3 & 25 & 83.3 & \\
\hline \multicolumn{6}{|l|}{48 hour } \\
\hline Present & 4 & 14.7 & 1 & 6.6 & $0.026^{s}$ \\
\hline Absent & 26 & 85.3 & 28 & 93.4 & \\
\hline \multicolumn{6}{|c|}{ Break through pain } \\
\hline Present & 12 & 50.0 & 2 & 13.3 & $0.002^{\mathrm{s}}$ \\
\hline Absent & 18 & 50.0 & 28 & 86.7 & \\
\hline
\end{tabular}

Chi-square test

$\mathrm{S}=$ significant, $\mathrm{ns}=$ not significant

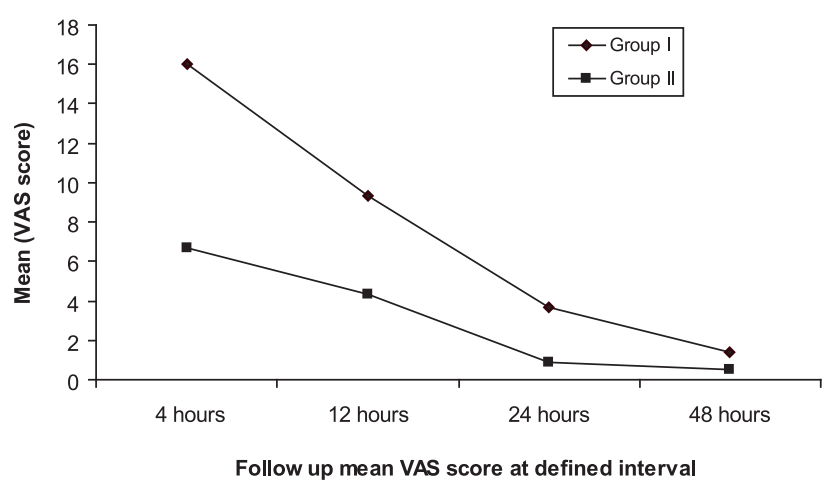

Fig.-2: Follow-up pain status

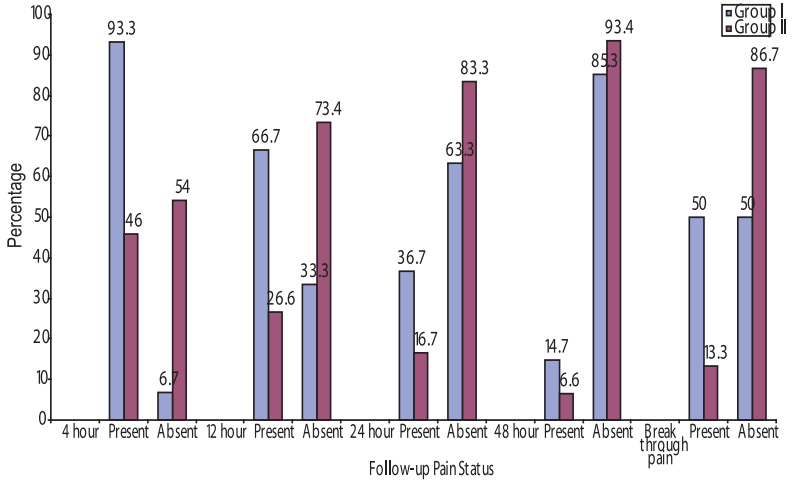

Fig.-3: Follow-up pain status 


\section{Discussion}

The degree of pain was significantly higher in group I at each interval.

The maximum intensity of pain was during the first 4 post operative hours and pain significantly reduced from 4 hours to 48 postoperative hours.

The results demonstrate that preoperative administration of rectal diclofenac and paracetamol as well as infiltration of local anesthetic in the incision line reduced the postoperative pain during recovery period and during the first 48 hours after operation; children who received both drugs recorded a lower pain rating scale. It is obvious that more reduction of postoperative pain due to synergistic effect of that above mention drugs.

All the patients in the present study irrespective of the group assignment, the pain score was never above VAS 30.

No adverse effects attributed to the combination of paracetamol and diclofenac were reported 14,15,16.

In the control group, two patients received rescue analgesia as per rectal diclofenac.

In the study group no patient needed rescue analgesia.

Pre -emptive analgesia prevent development of chronic pain ${ }^{17}$.

Combination of diclofenac and paracetamol has been shown to decrease narcotic consumption after operation in adults ${ }^{9}$. The study was done to emphasize the importance of giving analgesics for the child who complain of pain and to produce smooth recovery after surgery by decreasing immediate post operative pain with a simple, safe, cheap, available and acceptable drugs.

Hence the primary goals of pre-emptive analgesia are to decrease acute pain following tissue injury to prevent pathological modulation of the central nervous system (CNS) due to this pain and the development of chronic pain ${ }^{10}$. In this study we used Universal pain assessment tool (combination of VAS, Wong Baker, Activity tolerance and Face scale) ${ }^{11}$. Administration of analgesics and measurement of pain was double blind in both groups.

Surgery offers the most promising clinical setting for preemptive analgesia techniques because the timing of onset of the intense noxious stimulus is known 12. Owing to'protective' effect on the nociceptive system, preemptive analgesia has the potential to be more effective than a similar analgesic treatment initiated after surgery. ${ }^{2}$

The requirement of analgesic is only an indirect measure of pain and this can be confounded by patient factors such as varying pain thresholds, psychosocial makeup and cultural influences. ${ }^{13}$ The important point in this study was that none of the study patients experienced severe pain even when they coughed.

The combination of paracetamol and an NSAID was more effective than paracetamol or an NSAIDS alone in $85 \%$ and $64 \%$ of the studies, respectively. This conclusion is consistent with many previous expert reviews that recommend the use of combination analgesics. ${ }^{18}$

The recommendations from most of the previous expert reviews were based on logic rather than evidence, and in this study, we have attempted to provide the evidence.

The bioavailability of paracetamol suppositories is variable. It is approximately $80 \%$ of that of the tablets and the rate of absorption is slower, with maximum plasma concentrations achieved about 2 to 3 hours after administration ${ }^{8}$ No adverse effects attributed to the combination of paracetamol and NSAIDs were reported. ${ }^{6}$ In our present study, we have used $30 \mathrm{mg} /$ $\mathrm{kg}$ body weight of paracetamol and $1 \mathrm{mg} / \mathrm{kg}$ body weight diclofenac per rectum which were within the recommended dose suggested by Brian Aderson . ${ }^{18}$ In this present study, heart rate and blood pressure remained stable throughout the study period.

Postoperative pain is better controlled when analgesics are given on a regular basis and therefore unwanted breakthrough of pain and unnecessary suffering is avoided.${ }^{19}$ In this study we used analgesic at optimum dose and regular basis in both control group and study group.

The use of continuous NSAIDs will provide a consistent and constant level of background analgesia during major surgery but it has been suggested that NSAIDs should always be combined with other analgesics to treat breakthrough pain in the context of randomized practice ${ }^{20}$ Diclofenac may offer advantage over opioids with regards to convenience of use in the treatment of pain after surgery in children. Two studies indicate that children treated with diclofenac alone are less drowsy after surgery than their counterparts who have been treated with opioids alone for pain management. ${ }^{21}$ The ability of diclofenac to decrease PG production 
and therefore limit peripheral and central sensitization suggests a role of NSAIDs in preemptive analgesia. ${ }_{22}$ No evidence was found in the literature to support the use of intramuscular analgesia . ${ }^{23}$

Combining several analgesic modalities into a single analgesic regimen often referred to as multimodal analgesia may hold the greatest promise for limiting sensitization of the nervous systems by noxious stimuli. ${ }^{24}$ Effective pre-emptive analgesic techniques require multimodal interception of nociceptive inputs increasing threshold for nociception and blocking or decreasing nociceptive receptor activation ${ }_{25}$ Protocols which evaluate the long term functional and economic outcomes of aggressive pre-emptive multimodal analgesic interventions in place throughout the entire perioperative period against more usual perioperative pain therapy with single analgesia have yet to be performed. Until such studies suggest otherwise they advocate the use of a pre-emptive multimodal approach to analgesia using appropriate combinations and doses of systemic drugs, nerve block and neuraxial blocked. This offers the best opportunity for the reduction of pain and morbidity and the improvement of functionality. ${ }^{26}$ Paracetamol is a viable alternative to the NSAIDs especially because of the low incidence of adverse effects and should be preferred choice in high risk patients ${ }^{27}$. Our results showed that combination therapy was superior to each drug alone.

There are some limitations to the present study, such as difference of duration of preoperative pathology and psychosocial characteristics. The sample size is small, although most of similar studies have only less than 20 patients in each group.

It may be appropriate to combine paracetamol with diclofenac as pre-emptive but future studies are required, especially after major surgery. In such studies there should also be a specific focus on a potential increase in side effects from their combined use.

\section{Conclusion:}

This study concludes that administrations of multimodal pre-emptive analgesia control post operative pain effectively in children in view of both the degree of pain control and sustainability of pain free state.

\section{References:}

1. Lonnovist PA, Morton, NS 'post operative analgesia in infants and children. $\mathrm{Br} \mathrm{J}$ Anesth, 2005; 95: pp.59-68.
2. Dahl JB, Moiniche S. 'Pre-emptive analgesia' British Medical Bulletin, 2004; 71: pp.13-27.

3. Campbell, WI, Kendrick, RW \& Fee, JPH 'Balanced pre-emptive analgesia: does it work? A double -blind, controlled study in bilaterally symmetrical oral surgery, British Journal of Anaesthesia, 1998; 81: pp.727-30.

4. GottschalkA, Smith DS. 'New Concepts in Acute pain therapy: Preemptive Analgesia,' Amrican Family Physician, 2001; 63: pp.1979-84.

5. Hariharan S, Moseley S, Kumar A, Raju S. 'The effect of preemptive Analgesia in postoperative pain relief - A prospective double- blind randomized study,' American Academy of Pain Medicine, 2009; 10: pp.49-53.

6. Romsing, J, Moiniche, S, Dahl, JB, 'Rectal and Parenteral paracetamol and paracetamol in combination with NSAIDs, for postoperative analgesia'. Br J Anaesth, 2002; 88: pp. 215-26.

7. White, PF 'The changing role of non-opioid Analgesic Techniques in the management of postoperative pain', Anesthesia Analgesia, 2005; 101: pp. 05-22.

8. Afhami MR, Hassanzadeh P, Panahea JR. 'Preemptive analgesia with paracetamol (Acetaminophen) in postoperative pain,' Rawal Medical Journal, 2007; 32: 21-23.

9. Montgomery JE, Sutherland CJ, Kestin IG, Sneyd JR. 'Morphine Consumption in patients receiving rectal paracetamol and diclofenac alone and in combination, British Journal of Anaesthesia, 1996; 77: pp. 445-47.

10. Grape S, Tramer, MR. 'Do we need pre-emptive analgesia for the treatment of postoperative pain?'. Best pract Res clin Anaesthesiol , 2007; 21: pp.51-63.

11. Anderson BJ. 'Compairing the efficacy of NSAIDs and paracetamol in children,' Paediatric Anaesth, 2004; 14: pp.201-17.

12. Dalens B. Complications in paediatric regional anaesthesia in: Proceeding of the $4^{\text {th }}$ European Congress of Paediatric Anaesthesia, Paris, 1997.

13. Kissin,I 'Pre-emptive Analgesia at the Crossroad', Anesth Analg, 2005; 100: pp.754-56. 
14. Smith CM, Colvin JR. 'Control of acute pain in postoperative and post-traumatic situations,' Anaesthesia and intensive care medicine, 2005; 6: pp.02-06.

15. Arana A, Morton NS, Hansen TG. 'Treatment with Paracetamol in infants,' Acta Anaesthesiologica Scandinavica,' 2001; 45: pp. 20-29.

16. Berde B Charles \& Sethna F Navil 'Analgesic for the treatment of pain in children', New England Journal of Medicine, 2002; 347: pp.1094-02.

17. Breivik EK, Barkvoll P, Skovlund E. 'Combining diclofenac with acetaminophen or acetaminophen -codeine after oral surgery: a randomized, doubleblind single-dose study. Clinical Pharmacological Therapy, 1999; 66: pp. 625-35.

18. Riad W, Moussa A. 'Pre-operative analgesia with rectal diclofenac and /or Paracetamol in children undergoing inguinal hernia repair, Association of Anaesthetists of Britain and Ireland, 2007; 62: pp.1241-45.

19. Hiller A, Silvanto M, Savolainen S, Tarkkila P. 'Pro Paracetamol and diclofenac alone and in combination for analgesia after elective tonsillectomy,' Acta Anaesthesilogy Scand, 2004; 48: pp.1185-90.
20. Kokki H. 'Nonsteroidal Anti-inflammatory drugs for post operative pain: a focus on children, Paediatric Drugs, 2003; 5: pp.103-23.

21. Hyllested M, Jones S, Pedersen JL, Kehlet $\mathrm{H}$. 'Comparative effect of paracetamol, NSAIOs or their combination in postoperative pain management,' $\mathrm{Br}$ J Anesth, 2002; 88: pp.19914.

22. Ochroch EA, Mardini IA, Gottschalk A 'What is the role of NSAIDs in Pre-emptive Analgesia?' Drugs, 2003; 63: pp.2709-23.

23. Lunderberg S, Lonnovist PA' Update on systemic postoperative analgesia in children', Paediatric Anaesth, 2004; 14: pp.394-97.

24. Korpela R, Korvenoja P, Meretoja OA. 'MorphineSparing effect of acetaminophen in pediatric daycase surgery', American Society of Anesthesiologists, 1999, vol.91, pp.442-447.

25. Walker SM 'Pain in children recent advance and ongoing challenge', BJA, 2008; 101: pp.101-10.

26. Woolf CJ, Chong MS. 'Pre-emptive analgesia treating postoperative pain by preventing the establishment of central sensitization', International Anesthesia Research Society, 1993, 77: pp.362-79.

27. Katz J. 'Pre-emptive analgesia: Importance of timing,' Canadian Journal of Anesthesia, 2001; 48: pp.105-14. 